\title{
EDUCAÇÃO EM DIREITOS HUMANOS E PROCESSOS DE DE- MOCRATIZAÇÃO NO ENSINO FORMAL
}

\author{
HUMAN RIGHTS EDUCATION AND PROCESSES OF DEMOCRATIZATION IN \\ FORMAL SCHOOLING
}

\begin{abstract}
EDUCACIÓN EN DERECHOS HUMANOS Y PROCESOS DE EMOCRATIZACIÓN EN LA ENSEÑANZA FORMAL
\end{abstract}

\author{
Celma Tavares \\ Professora Doutora da Universidade Federal de Pernambuco (UFPE). \\ cftav@uol.com.br
}

\begin{abstract}
RESUMO: As práticas de educação em direitos humanos (EDH) buscam a formação do sujeito de direito, conjugando as esferas cognitivas, dos valores e das ações. Por isso, sua adoção como política pública é essencial à democracia e ao Estado de Direito. Embora seja uma nova área do conhecimento, seu âmbito de atuação tem possibilitado importantes experiências. Em Pernambuco, o trabalho de inserção da EDH na rede pública estadual de ensino desenvolveu-se de forma mais sistemática a partir de 2007. Objetivou-se com este artigo analisar em que medida as práticas de EDH no ensino formal se articulam e fomentam processos de democratização nas escolas pernambucanas. Com base nos dados deste estudo foi possível inferir que as ações e metodologias de EDH adotadas estimulam a participação, a autonomia e o estabelecimento de relações mais horizontais na construção coletiva do conhecimento. Consequentemente, tais relações vêm contribuindo para algumas transformações no espaço escolar, que tendem a propiciar melhores condições para que este ambiente esteja permeado por processos de democratização.
\end{abstract}

PALAVRAS-CHAVE: Educação em direitos humanos. Ensino formal. Processos de democratização.

ABSTRACT: The practices in Human Rights Education (HRE) pursue the formation of the subject of law, combining the spheres of cognition, values and action. Thus, to adopt them as public policy is vital to democracy and to the Rule of Law. Although it is a new area of knowledge, its field of action has been facilitating important experiences. In the State of Pernambuco, the insertion of HRE in the public school system was a process that started its systematic development as of 2007. This paper aims to analyze whether the practices of HRE in formal schooling are articulated and if they encourage processes of democratization in the schools of Pernambuco. It was possible, based on the data provided by this study, to assume that the adopted actions and methodologies of HRE motivate participation, autonomy and the establishment of horizontal relations in the collective construction of knowledge. Therefore, they contribute in some of the transformations that are happening in the space of school, that tend to propitiate better conditions so that processes of democratization may pervade this atmosphere.

KEYWORDS: Human rights education. Formal schooling. Processes of democratization.

RESUMEN: Las prácticas de educación en derechos humanos (EDH) buscan la formación del sujeto de derecho, articulando las esferas cognitiva, de los valores y de las acciones. Por eso, su adopción como política pública es esencial a la democracia y al Estado de Derecho. Aunque sea una nueva área de conocimiento, su ámbito de actuación ha posibilitado importantes experiencias. En Pernambuco, el trabajo de inserción de la EDH en la red pública estatal de enseñanza se desarrolló de forma más sistemática a partir de 2007. El objetivo de este artículo es analizar en qué medida las prácticas de EDH en la enseñanza formal se articulan y fomentan los procesos de democratización en las escuelas pernambucanas. Con base en los datos de esta investigación ha sido posible inferir que las acciones y metodologías de EDH adoptadas estimulan a la participación, la autonomía y las relaciones más horizontales en la construcción colectiva del conocimiento. Por consecuencia, estas relaciones vienen contribuyendo para algunas transformaciones en los espacios escolares, que tienden a propiciar mejores condiciones para que en este ambiente sea permeado por los procesos de democratización.

PALABRAS CLAVE: Educación en derechos humanos. Enseñanza formal. Procesos de democratización.

$\overline{\text { Artigo recebido em maio de } 2016}$

Aprovado em julho de 2016 


\section{1| INTRODUÇÃO}

As práticas de educação em direitos humanos (EDH) buscam a formação do sujeito de direito, conjugando as esferas cognitivas, dos valores e das ações. Sua finalidade é a construção de uma cultura de direitos humanos. Para tanto, sua adoção como política pública é essencial à democracia e ao Estado de Direito.

Desde o período de redemocratização, no Brasil, a EDH vem se afirmando nos processos educativos e se integrando cada vez mais à agenda governamental, o que se deu em especial, a partir da segunda metade dos anos 1990. Essa trajetória veio a atender a mobilização social interna, como também, a evolução ocorrida nesta área, no âmbito internacional.

Compreendendo a EDH como um processo sistemático e multidimensional, que orienta a formação do sujeito de direito (BRASIL, 2006), percebe-se a importância de que esta reforce os processos de democratização no país. Estes, segundo O'Donnell (1997), englobam a transição de um regime autoritário para um governo democrático e deste para a consolidação da democracia.

Neste contexto, Pernambuco tem se destacado pela experiência iniciada em 2007, que alternou ações de inclusão da EDH na rede pública estadual, por meio da disciplinaridade e da transversalidade.

O objetivo deste texto é analisar, a partir do trabalho realizado em Pernambuco, se as ações de EDH no ensino formal se articulam e fomentam processos de democratização, apresentando e discutindo as práticas e metodologias adotadas. Os dados aqui apresentados são parte da pesquisa "Educação em Direitos Humanos no Ensino Formal: uma análise da política educacional de Pernambuco", desenvolvida com o apoio da Fundação de Amparo à Ciência e à Tecnologia do Estado de Pernambuco.

O estudo realizou-se entre 2012 e 2013, na capital e sua região metropolitana e no interior do Estado (incluindo a Zona da Mata, o Agreste e o Sertão), abrangendo oito Gerências Regionais de Ensino (GREs) e sessenta municípios. Para fundamentar o processo metodológico do trabalho a opção foi pela abordagem qualitativa (LÜDKE; ANDRÉ, 1986); (GHEDIN; FRANCO, 2008), utilizando-se a análise de conteúdo (BARDIN, 1977) para o exame do material coletado - dados quantitativos, entrevistas, dados secundários e observação não participante. A opção por esses procedimentos e instrumentos permitiu a complementaridade de visões e formas de acercar-se sobre o objeto de pesquisa.

Foram aplicados questionários em 215 escolas públicas estaduais ${ }^{1}$, que constituem a principal base de análise deste texto, e que se centram nas práticas e metodologias adotadas no trabalho de EDH e sua articulação com os processos de democratização. Em um conjunto dessas escolas também foi possível desenvolver um trabalho de observação não participante. As entrevistas e dados secundários, por sua vez, contribuem à compreensão do processo de inserção da EDH na rede pública estadual de ensino de forma mais ampla. Em relação às primeiras, participaram gestores(as) e técnicos(as) da Secretaria de Educação de Pernambuco (SE/PE) e das GREs. No âmbito dos dados secundários, foram analisados relatórios, decretos e instruções normativas, todos relacionados à área.

\footnotetext{
${ }^{1}$ As escolas participantes foram incluídas com base em três aspectos: a) terem ofertado ou não terem ofertado a disciplina optativa de direitos humanos; b) desenvolverem projetos e/ou atividades de EDH; c) estarem distribuídas de forma a ter a representatividade nas oito GREs.
} 


\section{2 | PROCESSOS DE DEMOCRATIZAÇÃO NO CONTEXTO BRASILEIRO}

Democracia é uma palavra com diferentes acepções, Bobbio (2006), Dahl (1989), O'Donnell $(1997)^{2}$ são alguns dos autores que a analisaram e que contribuíram com importantes discussões para seu entendimento. A ideia de democracia que se utiliza neste artigo é a do regime político e da organização social os quais que oferecem as melhores condições para o respeito aos direitos humanos e para o exercício da cidadania ativa (BENEVIDES, 1991). Sobre os processos de democratização, O'Donnell (1997) os classifica em duas fases: uma primeira transição, que parte de um regime autoritário a um governo democrático; e uma segunda transição, que avança desse governo democrático até a consolidação da democracia.

Neste sentido, compreende-se que "o primeiro direito cidadão na democracia é o direito a ter um Estado que garanta os direitos de cidadania" (PNUD, 2004, p. 20). Esta afirmação, assinalada no Relatório sobre Democracia, Estado e Cidadania do Programa das Nações Unidas para o Desenvolvimento (PNUD), corresponde a uma questão fundamental, depois de décadas, nas que se buscou neutralizar a atuação estatal e dar-lhe conotações negativas, postulando o Estado mínimo como condição para o desenvolvimento econômico.

Diante dessa situação, é inevitável a mudança de uma democracia eleitoral para uma democracia de cidadania ${ }^{3}$, como proposto pelo PNUD, pois a organização de eleições é apenas um dos elementos do exercício democrático do poder.

Complementando esta análise, O'Donnell (2008) utiliza o conceito de "Estado angosto" (um Estado com atuação reduzida) para se referir aos Estados latino-americanos que, em sua maioria, são frágeis. Estes Estados, segundo o autor, apresentam resistências para "admitir como sujeitos de pleno direito a diversos setores sociais e suas demandas e identidades" e possuem "escassa capacidade para democratizar sociedades afetadas por uma longa e pesada história de desigualdade e heterogeneidade social" (O'DONNELL, 2008, p. 37). Assim, ao apresentar resistências para reconhecer os setores sociais como sujeitos de direito e ter reduzida capacidade de realizar experiências democráticas que invertam a lógica da desigualdade e injustiça social, os Estados descritos por O"Donnell revelam suas fragilidades e limitações que contribuem sobremaneira às disfunções presentes nas democracias latino-americanas.

O "Estado angosto", por sua vez, produz o que O'Donnell qualifica de "cidadania de baixa intensidade". Este tipo de cidadania pode ser entendido como a que se restringe ao campo formal e da democracia eleitoral e não avança para a organização e atuação social conjunta que impulsione uma participação ativa no âmbito das políticas públicas, que são o instrumento de concretização dos direitos sociais.

\footnotetext{
${ }^{2}$ Para Bobbio democracia é "um conjunto de regras (primárias ou fundamentais) que estabelece quem está autorizado a tomar as decisões coletivas e com que procedimentos". (BOBBIO, 1985, p. 21). Dahl, a chama poliarquia e a caracteriza "por sua contínua aptidão para responder às preferências de seus cidadãos". (DAHL, 1989, p. 13). O'Donnell a compreende como "democracia política que pode coexistir com diversos graus de democratização nos planos econômico, social e cultural". (O'DONNELL, 1997, p. 221).

${ }^{3} \mathrm{~A}$ distinção entre democracia eleitoral e de cidadania contém quatro argumentos básicos: 1 . A democracia encontra seu fundamento em uma concepção do ser humano como sujeito portador de direitos. 2. A democracia é uma forma de organização da sociedade que garante o exercício e promove a expansão da cidadania; estabelece regras para as relações políticas e para a organização e o exercício do poder. 3 . As eleições livres, competitivas e institucionalizadas, e as regras e os procedimentos para o exercício do governo são componentes essenciais da democracia; porém a democracia não se esgota nesta esfera. 4. O desenvolvimento da democracia na América Latina constitui uma experiência histórica única, caracterizada pelas especificidades intimamente relacionadas com os processos de construção da Nação e das sociedades latino-americanas. (PNUD, 2004, pp. 51-52)
} 
É amplamente conhecido que a primeira etapa de construção da democracia na região, após um amplo período de ditaduras, esteve relacionada à recuperação das liberdades civis. Nas últimas décadas, entretanto, o que se tem demandado são as garantias sociais, que para serem efetivas necessitam uma transformação social mais profunda, com o desmantelamento das estruturas de poder e das culturas de dominação.

Apesar de haver transcorrido mais de uma década da Carta Democrática Interamericana, da Organização dos Estados Americanos (OEA, 2001), a realidade, como explica O'Donnell (2008, p. 39) é que "na América Latina aprendemos que um Estado de baixa eficácia, efetividade e credibilidade pode coexistir com um regime de eleições razoavelmente competitivas e com a vigência de certas liberdades". Isso significa dizer que as fragilidades dos Estados latino-americanos, apontadas pelo autor, que resultam em sua baixa eficácia e credibilidade, apresentando-se como incapaz de atender às demandas reais de suas populações, ao contrário do que seria lógico esperar, não traz implicações restritivas para a manutenção do regime de eleições e do acesso a certas liberdades.

As pistas sobre a situação da democracia em Estados de baixa eficácia podem ser encontradas nos resultados do Latino-barômetro 2013, que incluem o Brasil. Seu relatório revela que "efetivamente apenas $8 \%$ dos habitantes adultos da região afirma que há democracia plena em seus países"; enquanto "a maior parte da população alega que não há democracia (9\%) ou então que esta tem grandes problemas (46\%)" (CORPORACIÓN LATINOBARÓMETRO, 2013, p. 33).

No âmbito do apoio à democracia, de acordo com os dados do já mencionado relatório, o seu crescimento em 2013, em comparação com a média encontrada para o período 1995-2013 ocorreu, por ordem decrescente, em onze países: Venezuela, Equador, Chile, Argentina, Bolívia, Brasil, Paraguai, República Dominicana, Colômbia, Guatemala e Peru. Ao mesmo tempo, a diminuição no apoio à democracia foi registrada em sete países, citados também, em ordem decrescente: Costa Rica, México, Uruguai, Panamá, Honduras, Nicarágua, El Salvador (CORPORACIÓN LATINOBARÓMETRO, 2013, p. 7 e 18).

Outra informação relevante e que tem relação direta com a discussão trazida neste texto se refere ao perfil do democrata encontrado na maioria dos países participantes. De forma geral, este perfil, que se manteve ao longo dos anos, mostrou que "quanto maior o grau de educação, maior o nível de apoio à democracia". Neste ponto é interessante notar a tendência a uma maior adesão à democracia por parte das pessoas com uma formação que lhes permite apreender princípios que regem o sistema democrático de maneira a valorá-los como importantes. Além disso, se verificou que "a educação é o único determinante sociodemográfico que importa ao definir os maiores níveis de democracia, porque na América Latina o nível educacional está diretamente relacionado ao salário e, consequentemente, ao nível socioeconômico da população" (CORPORACIÓN LATINOBARÓMETRO, 2013, p. 23).

Em relação ao contexto brasileiro, o que se verifica é que apesar do aumento do apoio à democracia, o país ainda está em sexto lugar entre os onze listados. Além disso, de acordo com análise do Latino-barômetro, considerando o conjunto de dados para o período 1995-2013 o Brasil "é um dos países que teve o apoio à democracia mais reduzido na região, tendo chegado ao seu ponto mais baixo em 2001, com apenas 30\%" de adesão ao regime democrático. A partir de 2006, esse percentual veio aumentando e se manteve em $40 \%$, chegando a $49 \%$ em 2013 . Por outro lado, o relatório chama a atenção para o alto percentual de apoio a um regime autoritário, que em 2013 chega a 19\%, assinalando que "é ainda importante a minoria autoritária no país" (CORPORACIÓN LATINOBARÓMETRO, 2013, p. 13). Essas informações servem para reforçar a ideia da continuidade do caráter disjuntivo ${ }^{4}$ da democracia brasileira. 


\section{3 | A IMPORTÂNCIA DA EDH PARA OS PROCESSOS DE DEMOCRATIZAÇÃO}

Os processos de democratização presentes na sociedade brasileira desde a última transição política têm convivido, como se apontou anteriormente, com a permanência de relações marcadas pelo autoritarismo; fato este que não pode ser subestimado. Para Pinheiro (1991) existe, na sociedade brasileira, um autoritarismo que afeta a todas as classes sociais e que se mantém independente do regime político vigente. O'Donnell (1997) o qualifica de "autoritarismo socialmente implantado" e esclarece que ele permeia tanto as macro quanto as micro dimensões do poder e é utilizado para marcar a distância social real ou teórica entre as pessoas.

Assim, os diversos ritos autoritários ${ }^{5}$ que formam parte da rede que legitima as desigualdades sociais e as violações aos direitos humanos ocorridas no país, onde o autoritarismo é socialmente implantado, contribuem sumamente a travar o processo de evolução para um regime plenamente democrático.

Nesta perspectiva, a educação em direitos humanos se mostra como importante caminho de ampliação dos processos de democratização na sociedade brasileira, partindo do âmbito educacional $^{6}$ a fim de ampliar-se para todos os demais. Para compreender as potencialidades da EDH nesta tarefa, é necessário conhecer o contexto de seu surgimento, os elementos que a compõem e a legislação que a sustenta.

Segundo Magendzo (1999, p. 4), a EDH se fez presente na realidade latino-americana nos anos 1980, quando se converteu em um pilar fundamental nos processos de (re)democratização. Nessa época, as organizações não governamentais (ONGs) foram os principais atores. Na década de 1990, por sua vez, houve mudanças significativas: maior interesse e protagonismo do Estado nessa área: a EDH foi ganhando terreno na educação formal; houve importante avanço na quantidade e qualidade de materiais educativos; a formação dos(as) docentes foi reforçada; e realizaram-se importantes ações de EDH no âmbito universitário.

Um exame, ainda que breve, do arcabouço legal que legitima a EDH em sistemas como o da Organização das Nações Unidas (ONU) ou da Organização dos Estados Americanos (OEA), assim como nos documentos brasileiros, permite que se tenha uma visão macro da sua relevância e do sentido que possui.

Desde a Declaração Universal dos Direitos Humanos (ONU, 1948) se destaca o papel da educação para o respeito aos direitos humanos. Em seguida, outros instrumentos da ONU incorporaram disposições relativas à EDH. Esta área foi ganhando relevância nos fóruns internacionais, em especial na Conferência Mundial de Direitos Humanos da ONU de 1993. Para consolidar o espaço desta prática, foi estabelecido o Decênio das Nações Unidas para a Educação na Esfera dos Direitos Humanos, entre 1995-2004 (ONU, 1994) e elaborado o Programa Mundial para a Educação em Direitos Humanos (ONU, 2004), iniciado em 2004 e com vigência até 2014. No

\footnotetext{
${ }^{4} \mathrm{O}$ carácter disjuntivo da democracia brasileira é um conceito criado por Caldeira e Houston para designar "os processos contraditórios de simultânea expansão e desrespeito aos direitos de cidadania". Em outras palavras, é este carácter que permite a convivência de instituições democráticas e das violações de direitos cada vez mais graves. (CALDEIRA, 2000, p. 343).

${ }^{5}$ Um desses ritos, amplamente conhecido e frequentemente identificado, encontra-se no uso da frase: Você sabe com quem está falando?, que revela a forma de sobrepor as relações pessoais às relações impessoais regidas pela lei em um sistema fortemente hierarquizado como o brasileiro, onde a regra principal é "cada um no seu lugar". Para mais informações ver Da Matta (1997).

${ }^{6}$ A democratização na educação, segundo Zientarski e Pereira (2009, p. 158), "pressupõe a democratização do conhecimento; a democratização do acesso, a garantia de permanência; e a democratização da gestão".
} 
sistema interamericano tem relevância para essa área, o Protocolo de São Salvador (OEA, 1988) e o Pacto Interamericano pela Educação em Direitos Humanos (OEA, 2010).

Além disso, a comunidade internacional considera que o direito à EDH faz parte do direito à educação ${ }^{7}$ e tem expressado, de maneira contínua, o consenso de que ela contribui decisivamente à realização dos demais direitos.

No Brasil, além da Constituição Federal, da Lei de Diretrizes e Bases da Educação, dos Parâmetros Curriculares, da maior parte das Diretrizes relacionadas à educação básica e do atual Plano Nacional de Educação, o campo normativo para a EDH tem também, como base outros dois documentos: o Programa Nacional de Direitos Humanos (PNDH) de 2009 e o Plano Nacional de Educação em Direitos Humanos (PNEDH) de 2006. Este último foi consequência de todo o movimento existente no contexto internacional, que possibilitou, em 2003, a criação do Comitê Nacional de Educação em Direitos Humanos, responsável pela elaboração do Plano como documento específico da educação nessa área.

A partir do PNEDH, a educação em direitos humanos no Brasil é entendida como:

\begin{abstract}
[...] um processo sistemático e multidimensional que orienta a formação do sujeito de direito articulando as dimensões de apreensão de conhecimentos historicamente construídos sobre direitos humanos; a afirmação de valores, atitudes e práticas sociais que expressem a cultura dos direitos humanos; a formação de uma consciência cidadã capaz de se fazer presente nos níveis cognitivos, sociais, éticos e políticos; o desenvolvimento de processos metodológicos participativos e de construção coletiva; o fortalecimento de práticas individuais e sociais geradoras de ações e instrumentos a favor da promoção, da proteção e da defesa dos direitos humanos, assim como da reparação de suas violações. (BRASIL, 2006, p. 25).
\end{abstract}

Esta conceituação, como um processo que orienta a formação do sujeito de direito, indica a finalidade principal da EDH e demarca o que a constitui e especifica ao mesmo tempo em que acompanha as concepções presentes nos documentos da área no âmbito internacional e interamericano.

Para expandir o alcance desse quadro normativo-institucional foram homologadas, em 2012, as Diretrizes Nacionais para a Educação em Direitos Humanos, pelo Conselho Nacional de Educação, em forma de Parecer e de Resolução (BRASIL, 2012a, 2012b). Entre outras questões, o documento, de caráter obrigatório, estabelece a EDH como um dos "eixos fundamentais do direito à educação" e designa a responsabilidade dos sistemas de ensino em sua efetivação, reforçando, assim, uma política educacional na área de direitos humanos. Além disso, sinaliza que a EDH ocorre com a inserção de conhecimentos, valores e práticas convergentes com os direitos humanos no currículo e no projeto político-pedagógico (BRASIL, 2012a, p. 12).

Nesta perspectiva, infere-se que a EDH compreendida como um dos eixos fundamentais do direito à educação e como processo formador do sujeito de direito, objetivando a construção de uma cultura de direitos humanos, influencia de forma contínua e positiva os processos de democratização, o que se dá em especial, ao contribuir para um maior nível de apoio à democracia, estando presente de maneira preponderante na formação do perfil do democrata latino-americano, segundo análise indicada no Latino-barômetro 2013.

\footnotetext{
${ }^{7} \mathrm{O}$ carácter disjuntivo da democracia brasileira é um conceito criado por Caldeira e Houston para designar "os processos contraditórios de simultânea expansão e desrespeito aos direitos de cidadania". Em outras palavras, é este carácter que permite a convivência de instituições democráticas e das violações de direitos cada vez mais graves. (CALDEIRA, 2000, p. 343).
} 


\section{4 | A EDH NO ENSINO FORMAL EM PERNAMBUCO COMO INSTRUMENTO PARA FOMEN- TAR OS PROCESSOS DE DEMOCRATIZAÇÃO}

A partir da década de 1990, como assinala Magendzo (1999), a EDH foi ganhando força na esfera do ensino formal na América Latina, passando a ser vista como a opção mais adequada para avançar no reconhecimento e na vigência dos direitos humanos e da democracia.

Esse caminho se justifica pela importância em incorporar a prática dos direitos humanos ao âmbito da educação sistemática porque a escola e cada um de seus agentes não podem se eximir do seu papel formador de princípios e valores, que igualmente estão ligados aos direitos humanos, pois no cotidiano de suas ações transmitem mais do que os conteúdos do currículo; imprimem modelos e condutas. Neste sentido, é relevante pontuar que apesar de a escola não ser o único lugar onde os conhecimentos sobre direitos humanos são construídos, "reconhece-se que é nela onde eles são apresentados de modo mais sistemático" (BRASIL, 2012a, p.13). Ou seja, apesar de existirem outros locais onde a EDH pode ocorrer, a escola reúne características importantes que lhe confere maiores condições de que os conhecimentos sobre direitos humanos estejam sistematicamente presentes.

Ao mesmo tempo, Candau et al. (1996, p. 14-15) explicam que, ao adotar a perspectiva dos direitos humanos, "a escola deveria exercer um papel de humanização a partir da socialização e da construção de conhecimentos e de valores necessários à conquista do exercício pleno da cidadania". Neste sentido, a EDH requer uma escola consoante com os princípios dos direitos humanos e que incorpore um processo de EDH que articule suas diferentes dimensões: dos saberes, dos valores e das ações.

Diante de um contexto de "Estado angosto" e de "cidadania de baixa intensidade", conforme explicitado anteriormente, como também da necessidade de estimular o pleno exercício da cidadania, é que a educação em direitos humanos se revela como um caminho efetivo para alcançar a "democracia de cidadania".

Nessa perspectiva, como um processo sistemático e multidimensional que orienta a formação do sujeito de direito, a EDH busca a promoção de processos educativos críticos e ativos, que sejam permanentes e transformem as mentalidades e atitudes (TAVARES, 2007), contribuindo, portanto, na trajetória dos processos de democratização das relações sociais e institucionais.

A EDH vem se afirmando nos processos educativos no Brasil, a partir do período de redemocratização e, desde a segunda metade dos anos 1990, vem se integrando cada vez mais à agenda governamental, conforme já indicado. Nos estados, o debate ganhou terreno; por um lado, com a instituição de Comitês de Educação em Direitos Humanos e, por outro, com ações desenvolvidas pelas Secretarias Estaduais de Educação.

Em Pernambuco, a experiência desenvolvida no ensino formal foi a única até o momento que superou o caráter de ação pontual, englobando o conjunto das escolas da rede pública estadual e servindo de referência para os demais estados brasileiros, além de ter sido reconhecida com o Prêmio Nacional de Educação em Direitos Humanos, em 2008, pela Secretaria de Direitos Humanos da Presidência da República.

O trabalho foi iniciado em 2007 quando se definiu de forma mais sistemática uma política de educação para o sistema estadual de ensino, fundamentada no eixo - Educação como formação para a cidadania. Para dar materialidade a essa política, foi organizado um conjunto de ações para a inserção da EDH em sua estrutura interna e nas escolas da rede pública estadual.

\footnotetext{
${ }^{8}$ Nas décadas de 1980 e 1990 havia sido iniciado um trabalho nesta área, mas com um caráter menos sistemático.
} 
Essa trajetória pode ser dividida em duas fases: uma que começa em 2007 e vai até 2010 e outra iniciada em 2011 e que continua atualmente. Na primeira etapa, que atingiu toda a rede de ensino, a proposta de inclusão da EDH foi feita por meio da disciplinaridade, com a oferta da disciplina optativa de direitos humanos no currículo escolar e também da transversalidade, como tema gerador dos projetos político-pedagógicos das escolas, com ações voltadas a integrar os vários setores da SE/PE. Na segunda etapa, a opção é pela transversalidade nas escolas de ensino fundamental e de ensino médio da rede regular, e pela disciplinaridade nas escolas integrais de ensino médio, com a oferta da disciplina obrigatória de direitos humanos ${ }^{9}$. Essa diferenciação de opções assinala o redirecionamento da política dentro do mesmo governo.

Nesse percurso, realizaram-se um conjunto de iniciativas, destacando-se entre 2007 e 2010 a criação da Gerência de Educação em Direitos Humanos (GEDH) ${ }^{10}$; a atualização curricular, com implantação da disciplina optativa de direitos humanos ${ }^{11}$; as ações de transversalização do conteúdo de direitos humanos, como tema gerador do projeto político-pedagógico das escolas; as ações para integrar as atividades dos vários setores da SE/PE e o processo formativo ${ }^{12}$. A partir de 2011, teve destaque a continuidade do processo formativo, centrando-se em formações temáticas, com a realização de 17 Fóruns de EDH, para discutir as Diretrizes Nacionais da Educação em Direitos Humanos, um em cada GRE e a distribuição de alguns materiais, como o Caderno de Direitos Humanos e o Caderno de Educação Ambiental. Nesta direção, percebe-se uma alteração no perfil das atividades quando comparadas com os anos anteriores, sendo estas atualmente mais específicas e relacionadas com algumas áreas.

$\mathrm{Na}$ esfera das oito GREs, incluídas no estudo, as estratégias de ação foram diferenciadas de acordo com a realidade das escolas atendidas. Assim, uma investiu no combate à homofobia, outra priorizou o campo das relações étnico-raciais, uma terceira direcionou as ações para a área de gênero, duas priorizaram o trabalho de educação para a paz e outras três enfocaram a mediação de conflitos. Ao mesmo tempo, foram identificadas atividades mais estruturadas e sistemáticas que outras, no sentido de estimular o trabalho docente, como a criação de comissões de direitos humanos, a realização de fóruns e de projetos específicos na área. Aqui se ressalta a riqueza da diversidade dos modos de fazer, mesmo considerando que este estudo representa um recorte em relação ao sistema educacional.

\footnotetext{
${ }^{9}$ São em torno de 1000 escolas na rede estadual, sendo 300 escolas integrais de ensino médio (com atividades durante todo o dia). Na estrutura da SE/PE a Secretaria Executiva de Desenvolvimento da Educação é responsável pelas escolas da rede regular e a Secretaria de Educação Profissional pelas escolas integrais.

${ }^{10}$ A Gerência foi criada pelo Decreto n. ${ }^{\circ}$ 30.362, de 17 de abril de 2007 (PERNAMBUCO, 2007), que estabeleceu como competências elaborar, implementar e acompanhar a política de educação em direitos humanos, diversidade e cidadania da SE/PE.

${ }^{11}$ A implantação da matriz curricular unificada para os níveis e modalidades de ensino foi definida por meio da Instrução Normativa 03/2008, de 04 de março de 2008 (PERNAMBUCO, 2008), de forma a garantir a equidade na oferta das disciplinas e na carga horária de um mesmo nível de ensino.

${ }^{12} \mathrm{O}$ processo formativo iniciou-se em 2007 com uma formação inicial sobre EDH para a equipe técnica da GEDH, e outros tipos de atividades, a exemplo de seminários e palestras. Em 2008, teve início uma formação continuada específica para os(as) 1.200 professores(as) da disciplina de direitos humanos, tendo sido igualmente realizada nos anos de 2009 e 2010. Ao mesmo tempo, ocorreram formações nas várias áreas temáticas que compõem a GEDH, como educação indígena, educação ambiental, educação fiscal, educação étnico-racial, etc. (PERNAMBUCO, 2010). Com a opção de trabalhar a EDH apenas pela transversalidade, a partir de 2011 , o foco da formação foi modificado. Atualmente o trabalho ocorre por meio da articulação de temáticas, tanto no que diz respeito à formação dos(as) profissionais, como ao que é trabalhado em sala de aula.
} 


\subsection{As práticas e metodologias adotadas}

As escolas, por sua vez, são o reflexo do movimento dessa realidade, mas também desenvolveram trajetórias próprias, o que demonstra sua capacidade de produzir conhecimentos e alternativas pedagógicas. Desta maneira, o grau de articulação, estruturação e realização da EDH dependeu de uma série de fatores, entre os quais, o maior ou menor envolvimento da comunidade escolar, a realização de alguns projetos que se destacaram nesse percurso de construção e a forma de organização do currículo, para o conteúdo de direitos humanos: se disciplinar ou transversal.

Em relação a este último aspecto, é importante destacar, por um lado, que as Diretrizes Nacionais indicam que a EDH pode fazer-se presente no currículo "pela transversalidade, por meio de temas relacionados aos direitos humanos e tratados interdisciplinarmente; como conteúdo específico de uma das disciplinas já existentes no currículo; de maneira mista, ou seja, combinando transversalidade e disciplinaridade" (BRASIL, 2012a, p. 12). Por outro lado, é preciso assinalar a existência de dois modelos diferenciados na mesma rede: a disciplinaridade em algumas escolas e a transversalidade na maior parte delas ${ }^{13}$. Apesar disso, as opiniões da maioria dos(as) profissionais das 215 escolas participantes do estudo aponta como mais efetivo para o trabalho de EDH mesclar as duas formas: $51 \%$ no Recife e região metropolitana e 54\% no interior do Estado.

$\mathrm{O}$ trabalho de EDH nas escolas estudadas vem sendo construído com base em diferentes estratégias, materiais, conteúdos e enfoques. A abordagem é feita utilizando-se a exposição dialogada, trabalhos em grupo, pesquisa, cine educação, produção de vídeo, oficinas, seminários, rodas de diálogo e atividades extraclasse. Entre os conteúdos destacam-se os seguintes temas: criança e adolescente; violência; gênero, direitos civis e políticos; história dos direitos humanos; movimentos sociais; meios de comunicação; cidadania; ética; questão étnico-racial; bullying; e diversidade sexual. Esses temas são trabalhados com o emprego de textos, leis, livros, poesias e documentos oficiais, como o Estatuto da Criança e do Adolescente, a Declaração Universal dos Direitos Humanos e a Constituição Federal.

Alguns exemplos podem ilustrar a variedade de caminhos utilizados pelas escolas visitadas. Uma delas aproveita o conteúdo de ensino religioso, que é dada em forma de seminário, para abordar temas de direitos humanos nas turmas de Educação de Jovens e Adultos (EJA). Discutem temas como preconceito religioso, gravidez na adolescência, doenças sexualmente transmissíveis, Estatuto da Criança e Adolescente, etc. Outra escola definiu um cronograma para que o(a) professor(a) de cada componente curricular trabalhasse em sala de aula a articulação da disciplina com o conteúdo de direitos humanos. Assim, na disciplina de língua inglesa, por meio da discussão de uma música, foram trabalhadas as diferenças culturais, as violações de direitos e os valores necessários à convivência social. Em matemática, utilizou-se a análise de gráficos e tabelas para discutir a questão da saúde. Outros exemplos são de escolas que investem em atividades de protagonismo juvenil ou têm inserido o tema direitos humanos em feira de ciências, em gincanas e em várias festividades.

\footnotetext{
${ }^{13}$ É importante chamar a atenção para as implicações resultantes desses dois modelos. Quando o conteúdo de direitos humanos é colocado no currículo de forma disciplinar, as práticas acabam restritas ao componente curricular, ficando restrito à sala de aula e à disciplina. Quando o conteúdo é organizado de forma transversal, ou a abordagem se restringe aos componentes da área de humanas, sem transversalizar todas as disciplinas, ou o trabalho é feito por meio de projetos e de atividades pontuais, sem atingir toda a comunidade escolar, como é o propósito da EDH ao transversalizar o currículo.
} 
Dessas estratégias decorrem mudanças no ambiente escolar, algumas de efeito mais imediato e outras que serão percebidas em médio e longo prazos. Dois exemplos: o aprendizado sobre o Estatuto da Criança e do Adolescente em escola do Recife, com o projeto "Viver com o ECA", que tem possibilitado o conhecimento sobre os direitos e responsabilidades e a mudança de comportamento da comunidade escolar em relação à homofobia em escola da região metropolitana, que possibilitou o retorno de estudantes homossexuais que haviam abandonado a escola, o que foi possível com um trabalho contínuo de formação por meio do projeto Homofobia, Lesbofobia e Transfobia no contexto escolar, que foi premiado em 2010 na categoria escolas públicas do Prêmio Nacional de Educação em Direitos Humanos da Secretaria de Direitos Humanos da Presidência da República.

\subsection{A contribuição para os processos de democratização}

Cabe, neste momento, passar a refletir acerca da potencialidade das ações de EDH no ensino formal para articular e fomentar processos de democratização, com base nas práticas e metodologias adotadas nas escolas estaduais de Pernambuco.

Considerando que a escola é o espaço educativo onde se define com intencionalidade o que se ensina e o que se aprende, estando mais fortemente permeada por tensões e conflitos, mas que ao mesmo tempo é também um espaço privilegiado para estimular a transformação da realidade, percebe-se que a adoção de práticas como as exposições dialogadas, as dinâmicas e atividades em grupo possibilitam a participação, a autonomia e o estabelecimento de relações mais horizontais na construção coletiva do conhecimento.

Os estímulos à participação e ao protagonismo juvenil, por sua vez, estão em consonância com o estabelecimento de processos de democratização no âmbito do ensino-aprendizagem e no campo da convivência social, porque permitem a pluralidade de ideias, a análise crítica e a expressão de uma cidadania ativa, congregando, portanto, a esfera dos conhecimentos, dos valores e atitudes e das capacidades para a ação.

Estes aspectos são visíveis no dia a dia dos trabalhos quando os(as) estudantes debatem seus diferentes pontos de vista e se posicionam em relação a questões como desigualdade de gênero, racismo, homofobia, etc. O resultado é uma formação mais qualificada, que proporciona momentos de produção analítica dos(as) estudantes (em lugar da simples reprodução dos conteúdos), como por exemplo, na elaboração de um cordel por estudantes do ensino médio que em uma de suas estrofes destaca:

Portanto, prezado amigo, vou Ihe falar com respeito, não julgue pela aparência, veja as pessoas direito,

fique fora do racismo, e viva sem preconceito!

Outro exemplo interessante foi a abordagem do tema da ditadura em uma das aulas do componente de História que proporcionou aos(às) estudantes do ensino fundamental pesquisar sobre violações de direitos humanos nesse período, como por exemplo, a supressão de direitos fundamentais, as prisões ilegais e as torturas. Com o trabalho, os grupos participantes da atividade se mostraram sensibilizados e indignados com os vários tipos de tortura praticadas contra os(as) militantes políticos contrários à ditadura.

Mais um exemplo que indica a contribuição da EDH para os processos de democratização se relaciona a uma discussão sobre estereótipos e papéis de gênero durante a disciplina de direitos humanos no ensino médio e que esteve permeada por uma percepção mais crítica acerca dessa 
problemática, tendo durante o debate comentários como estes: "Não é porque a pessoa escolhe esta ou aquela profissão que isso interfere na opção sexual". (Aluno) e "Da mesma forma que a mulher pode estar no fogão, o homem também pode". (Aluna)

O potencial destas práticas se amplia quando aliadas ao desenvolvimento de projetos interdisciplinares sobre direitos humanos. Por meio de tais projetos, é possível oportunizar a articulação do aprender a ser, a fazer, a conviver e a conhecer (DELORS, 2001), pois estes admitem enfatizar questões mais amplas inter-relacionadas com o contexto social; lidar com fatos concretos; trabalhar com situações-problema; promover a criatividade e a criticidade; incluir reformulações interpretativas, etc.

Assim, partindo do principio de que somente o diálogo é capaz de gerar um pensamento crítico (FREIRE, 2005), porque o saber democrático não pode ocorrer de forma autoritária, é que se percebe a necessidade de assegurar práticas e metodologias que promovam processos de democratização, que estimulem o pensar coletivo e um trabalho de ação-reflexão-ação a fim de contribuir à construção da autonomia das pessoas, em um processo libertário e de vivência dos direitos. No âmbito da EDH essa concepção "desenvolve os processos de formação de uma cidadania ativa, que se materializa no dia a dia, no conhecimento das leis e normas, dos deveres, direitos e na forma de exigi-los e aplicá-los, buscando a garantia do acesso aos bens sociais para todas as pessoas" (SILVA; TAVARES, 2010, p. 102).

Portanto, é possível assim inferir que as práticas e metodologias adotadas no trabalho de EDH nas escolas públicas estaduais pernambucanas vêm contribuindo para algumas transformações no espaço escolar, de acordo com os(as) profissionais das escolas participantes, sobretudo com resultados relacionados com a mudança de comportamento, que foi a maioria das opiniões; mas também os que se situam no campo da aprendizagem; e os referentes à conscientização. Essas mudanças tendem a propiciar melhores condições para que o ambiente escolar esteja permeado por processos de democratização, além de possuir o potencial de expansão para outros âmbitos da organização social.

Além disso, a contribuição da experiência analisada para a ampliação dos processos de democratização reside em seu caráter sistemático e contínuo. Sobre este aspecto, Schilling (2008) chama a atenção para o fato de que são muitas as experiências de EDH no país, experiências essas que vêm sendo realizadas por distintos atores sociais, em diversos níveis, mas que se apresentam de forma heterogênea e muitas vezes dispersas. Ao mesmo tempo, Candau (2008) destaca que a maior parte das atividades de EDH enfoca apenas a transmissão de conhecimentos sobre direitos; se concentra apenas na esfera da sensibilização, e sua utilização se restringe a determinados momentos e atividades específicas, como as datas comemorativas.

É preciso, portanto, compreender que um processo de EDH pretende:

a) formar sujeitos de direitos;

b) impulsionar o processo de empoderamento a fim de favorecer a participação ativa da sociedade;

c) desenvolver processos de construção de sociedades democráticas e humanas, entre os quais se encontra o eixo da educação para o "nunca mais" (CANDAU, 2008, p. 289-290).

\footnotetext{
${ }^{13}$ A educação para o nunca mais, segundo Sacavino (2000, p. 44), "promove o sentido histórico e resgata a memória em lugar do esquecimento". [...] "Supõe quebrar a "cultura do silêncio" e da impunidade presente na maioria de nossos países, formando para a mudança, a participação, a transformação e a construção de sociedades verdadeiramente democráticas, humanas, justas e solidárias".
} 
Por outro lado, é necessário reconhecer que o trabalho na rede pública estadual de Pernambuco ainda encontra-se em desenvolvimento; que passou por fases distintas, e que necessita ajustes e aperfeiçoamento em diversos campos. Em especial, nos âmbitos das instâncias relacionadas à gestão democrática, como conselho escolar, grêmio estudantil e atividades que aproximem a comunidade do entorno da escola, que ainda tem incluído, de forma tímida, a discussão sobre direitos humanos.

Também não se desconsidera as dificuldades em empreender um trabalho na área de EDH geradas pela sua contraposição aos princípios que norteiam as políticas educacionais das últimas décadas, que passaram a priorizar um modelo de organização do sistema escolar baseado na qualidade total e na avaliação pautada por um sistema classificatório, gerador de um ranking das "melhores" escolas.

E igualmente reconhece-se a existência de limitações na experiência de Pernambuco, relacionadas principalmente à insuficiência de formação e de materiais, à restrição de recursos humanos e financeiros, e à ausência de monitoramento mais sistemático do trabalho desenvolvido nas escolas. Pontos que precisam ser aprofundados com o objetivo de consolidar o processo de EDH em curso.

\section{5 | CONSIDERAÇÕES FINAIS}

Os processos de democratização são fundamentais para o avanço da consolidação da democracia nos países latino-americanos. Compreendendo a democracia como o regime político e da organização social que oferece as melhores condições para o respeito aos direitos humanos, destaca-se a importância de que a EDH reforce ditos processos e contribua na direção da "democracia de cidadania".

Ao mesmo tempo, o Brasil continua sendo um país que avançou em algumas áreas após sua redemocratização, mas que mantém o caráter disjuntivo (CALDEIRA, 2000) de sua democracia junto com um autoritarismo socialmente implantado (O'DONNELL, 1997), que segue legitimando as graves violações de direitos humanos.

Neste contexto, a EDH se mostra como importante caminho de ampliação dos processos de democratização na sociedade brasileira, tendo se integrado à agenda governamental de forma mais organizada a partir da década de 1990.

Nesta trajetória de afirmação da EDH nos espaços educativos, Pernambuco vem desenvolvendo experiência na rede pública de ensino que superou o caráter pontual, englobando todas as escolas estaduais. Para tanto, foi criado um arcabouço normativo-institucional na SE/PE, que possibilitou a estrutura necessária e as diretrizes sobre os quais as ações se realizam. $O$ trabalho alternou ações de inclusão da EDH na rede pública estadual por meio da disciplinaridade e da transversalidade, com as vantagens e desvantagens de cada modelo.

O trabalho nas escolas veio sendo construído com base em diferentes estratégias, materiais, conteúdos e enfoques. Como todo processo, a inserção da EDH teve tempos, espaços, movimentos, condições e apreensões dos conteúdos com ritmos diferentes. Por isso, em muitos aspectos, o trabalho em Pernambuco segue os parâmetros pedagógicos da EDH (CANDAU, 2000; MAGENDZO, 2010; SILVA; TAVARES, 2013), conjugando as esferas cognitiva, ético-valórica e atitudinal. Contudo, enquanto processo, ocorreram momentos de maior e menor aproximação desses parâmetros.

Com base na análise dos dados deste estudo e com o olhar dirigido à contribuição da EDH aos processos de democratização, percebe-se que a adoção de práticas como as exposições 
dialogadas, as dinâmicas e atividades em grupo que têm permeado o trabalho das escolas possibilitam a participação, a autonomia e o estabelecimento de relações mais horizontais na construção coletiva do conhecimento.

Igualmente é possível inferir que as práticas e metodologias adotadas no trabalho de EDH nas escolas públicas estaduais pernambucanas vêm contribuindo para algumas transformações no espaço escolar, que tendem a propiciar melhores condições para que o ambiente escolar esteja permeado por processos de democratização, além de possuir o potencial de expansão para outros âmbitos da organização social.

Por fim, ao mesmo tempo em que é destacada a riqueza e diversidade dos modos de fazer, é preciso ponderar que a institucionalização da EDH está em desenvolvimento, tratando-se de um processo que precisa consolidar-se. 


\section{Referências}

BARDIN, L. Análise de conteúdo. Lisboa: Edições 70, 1977.

BENEVIDES, M. V. A cidadania ativa. São Paulo: Ática, 1991.

BOBBIO, N. El futuro de la democracia. Barcelona: Plaza \& Janes Editores, 1985.

BRASIL. Ministério da Educação. Secretaria Especial dos Direitos Humanos. Plano Nacional de Educação em Direitos Humanos. Brasília, DF: MEC; SEDH, 2006.

Parecer CNE/CP $n^{\circ}$ 8, aprovado em 6 de março de 2012. Diretrizes Nacionais para a Educação em Direitos Humanos. Diário Oficial da União. Brasília, DF, 30 maio 2012a. Seção 1, p. 33.

Resolução CNE/CP n 01, de 30 de maio de 2012. Estabelece Diretrizes Nacionais para a Educação em Direitos Humanos. Diário Oficial da União. Brasília, DF, 31 maio 2012b. Seção 1, p. 48.

CALDEIRA, T. Cidade de muros: crime, segregação e cidadania em São Paulo. São Paulo: Edusp, 2000.

CANDAU, V. Educação em direitos humanos no Brasil: realidade e perspectivas. In: CANDAU, V.; SACAVINO, S. (Org.). Educar em direitos humanos: construir democracia. Petrópolis: Vozes, 2000. p. 72-99.

Educação em direitos humanos: questões pedagógicas. In: BITTAR, E. (Org.). Educação e metodologia para os direitos humanos. São Paulo: Quartier Latin, 2008. p. 285-298.

CANDAU, V. et al. Tecendo a cidadania: oficinas pedagógicas de direitos humanos. Petrópolis: Vozes, 1996.

CORPORACIÓN LATINOBARÓMETRO. Latinobarómetro: opinión pública latinoamericana. Santiago, Chile, nov. 2013. Disponível em: <www.latinobarometro. org>. Acesso em: 05 nov. 2014.

DAHL, R. La poliarquía. Madrid: Tecnos, 1989.

DA MATTA, R. Carnavais, malandros e heróis: para uma sociologia do dilema brasileiro. Rio de Janeiro: Rocco, 1997.

DELORS, J. Educação: um tesouro a descobrir. São Paulo: Cortez; Brasília: MEC-UNESCO, 2001.

FREIRE, P. Pedagogia do oprimido. 49. reimp. Rio de Janeiro: Paz e Terra, 2005.

GHEDIN, E.; FRANCO, M. A. Questões de método na construção da pesquisa em educação. São Paulo: Cortez, 2008.
IIDH. Informe interamericano de la educación en derechos humanos: un estudio en 19 países. Compendio de cinco informes 2002-2006. San José, Costa Rica: IIDH, 2009. p. 51-80. Parte I, Desarrollo normativo 2002.

LÜDKE, M.; ANDRÉ, M. Pesquisa em educação: abordagens qualitativas. São Paulo: EPU, 1986.

MAGENDZO, A. (Org.). La educación en derechos humanos en América Latina: una mirada de fin de siglo. Costa Rica: IIDH, 1999.

(Org.). Pensamiento e ideas-fuerza de la educación en derechos humanos en Iberoamérica. Santiago, Chile: OIE; Orealc; Unesco, 2010.

O'DONNELL, G. Contrapuntos: ensayos escogidos sobre autoritarismo y transición. Buenos Aires: Paidós, 1997.

. Hacia un estado de y para la democracia. En: Democracia, estado, ciudadanía: hacia un estado de y para la democracia en América Latina. Lima, Perú: FIMART S.A.C., 2008. p. 25-62.

OEA. Carta democrática interamericana. Lima, Perú, 2001. Asamblea de la organización de los estados americanos.

Pacto interamericano por la educación en derechos humanos. Lima, Perú, 2010. Aprobado en la cuarta sesión plenaria de la 40 asamblea general de la OEA.

Protocolo adicional à Convenção Americana sobre direitos humanos em matéria de direitos econômicos, sociais e culturais: protocolo de San Salvador. San Salvador, El Salvador, 1988. Assinado na assembleia geral da ONU, $18^{\circ}$ período ordinário de sessões.

ONU. A década das Nações Unidas para educação em matéria de direitos humanos 1995-2004. Proclamada pela Resolução n. ${ }^{\circ}$ 49/184, em 23 de dezembro de 1994. Nova lorque, 1994.

Declaração Universal dos Direitos Humanos, 1948, Paris. Adotada e proclamada pela Resolução $n^{\circ}$ 217 A (III), em 10 de dezembro de 1948. Nova lorque, 1948.

Programa mundial para a educação em direitos humanos. Proclamado pela Resolução n. ${ }^{\circ}$ 59/113-A, em 10 de dezembro de 2004. [S.I.], 2004.

PERNAMBUCO. Decreto $n^{\circ} 30.362$, de 17 de abril de 2007. Aprova o regulamento da Secretaria de Educação, e dá outras providências. Diário Oficial do Estado. Recife, 18 abr. 2007. 
PERNAMBUCO. Instrução Normativa n. ${ }^{\circ}$ 03/2008, de 4 de março de 2008. Dispõe sobre a implantação/operacionalização das matrizes curriculares nas escolas da rede estadual de educação a partir do ano letivo de 2008. Diário Oficial do Estado. Recife, 4 mar. 2008.

PERNAMBUCO. Secretaria de Educação. Gerência de Educação em Direitos Humanos. Relatório de atividades 2007-2010. Recife: SE/GEDH, 2010.

PINHEIRO, P. S. Autoritarismo e transição. Revista USP, São Paulo, n. 9, mar./abr./maio, 1991. Dossiê Violência.

PNUD. Democracia, estado, ciudadanía: hacia un estado de y para la democracia en América Latina. Lima-Perú: Ed. FIMART S.A.C., 2008. Dirección regional para América Latina y el Caribe del PNUD.

La democracia en América Latina: hacía una democracia de ciudadanas y ciudadanos. Buenos Aires: Aguilar, Altea, Taurus, Alfaguara, 2004.

SACAVINO, S. Educação em direitos humanos e democracia. In: CANDAU, V.; SACAVINO, S. (Org.). Educar em direitos humanos: construir democracia. Rio de Janeiro: DP\&A Editora, 2000. p. 36-48.
SCHILLING, F. O direito à educação: um longo caminho. In: BITTAR, E. (Coord.). Educação e metodologia para os direitos humanos. São Paulo: Quartier Latin, 2008. p. $57-91$.

SILVA, A. M. M.; TAVARES, C. El papel de la educación en derechos humanos en la formación de una ciudadanía activa. Revista Interamericana de Educación para la Democracia, v. 3, n. 1, p. 95-107, abr. 2010.

Educação em direitos humanos no Brasil: contexto, processo de desenvolvimento, conquistas e limites. Educação, Porto Alegre, v. 36, n. 1, p. 50-58, jan./ abr. 2013. Impresso.

TAVARES, C. Educar em direitos humanos, o desafio da formação dos educadores numa perspectiva interdisciplinar. In: GODOY, R. et al. Educação em direitos humanos: fundamentos teóricos-metodológicos. João Pessoa: Editora da UFPB, 2007.

ZIENTARSKI, C.; PEREIRA, S. Os caminhos para a democratização da educação no Brasil: qual o papel dos educadores neste processo? Revista HISTEDBR, Campinas, n. 34, p. 154-166, jun. 2009. Disponível em: <http://www.fe.unicamp.br/revistas/ged/histedbr/article/ view/3853/3269>. Acesso em: 05 nov. 2014. 